Revista de Ensino em Artes, Moda e Design

Dossiê 6

A modelagem integrada ao projeto de Moda no âmbito do ensio

\title{
A ESCOLINHA DE ARTES DO RECIFE COMO ESPAÇO INCLUSIVO PARA PESSOAS COM DEFICIÊNCIA
}

The Escolinha de Artes in Recife as an inclusive space for people with deficiency

La Escolinha de Artes de Recife com un espacio inclusivo para las personas con deficiencia

Ediel Barbalho de A. Moura ${ }^{1}$

\footnotetext{
${ }^{1}$ Especialista em Educação na perspectiva inclusiva, pela UPE. Graduado em Licenciatura em Artes Visuais, pela UFPE. Atua como Arte/educador na Escolinha de Arte do Recife (EAR) e em ONGs da Região Metropolitana de Recife. ORCID ID: https://orcid.org/0000-0002-6249-8540 Currículo Lattes: http://lattes.cnpq.br/9468327713195742
} 


\title{
Resumo
}

A Escolinha de Arte do Recife desde sua origem, em 1953, vem desenvolvendo ações arte/educativas para todo tipo de público. Notada a relevância histórica da instituição para a arte/educação pernambucana, foram investigados registros bibliográficos, históricos, documentais, como também as práticas arte/educativas desenvolvidas nela. A partir da trajetória da EAR, comentamos a respeito da visão inclusiva da instituição e como ela contribuiu, e ainda contribui, para a construção de práticas na perspectiva inclusiva para pessoas com deficiência. Então conforme registros bibliográficos, de documentos e da realização e análise de uma atividade arte/educativa desenvolvida na atualidade, observou-se que a Escolinha foi e é um espaço onde experiências estéticas sensoriais são trabalhadas pela perspectiva da inclusão.

Palavras-chave: Arte; Educação; Inclusão.

\begin{abstract}
The Escolinha de Arte do Recife since its origin, in 1953, has been developing art / educational activities for all types of public. Noting the historical relevance of the institution for Art / education in Pernambuco, bibliographical, historical and documentary records were investigated, as well as the art / educational practices developed there. Based on EAR's trajectory, we comment on the institution's inclusive vision and how it has contributed, and still contributes, to the construction of practices in an inclusive perspective for $\mathrm{p}$

eople with disabilities. So according to bibliographic records, documents and the realization and analysis of an art / educational activity developed today, it was observed that Escolinha was, and is, a space where sensory aesthetic experiences are worked from the perspective of inclusion.
\end{abstract}

Keywords: Art; Education; Inclusion.

\section{Resumen}

La Escolinha de Arte do Recife desde su origen, en 1953, viene desarrollando actividades artísticas / educativas para todo tipo de público. Teniendo en cuenta la relevancia histórica de la institución para el Arte / educación en Pernambuco, se investigaron registros bibliográficos, históricos y documentales, así como las prácticas arte / educativas que alli se desarrollan. A partir de la trayectoria de EAR, comentamos la visión inclusiva de la institución y cómo ha contribuido, y sigue contribuyendo, a la construcción de prácticas en una perspectiva inclusiva para las personas con discapacidad. Así, de acuerdo con registros bibliográficos, documentos y la realiza- 
ción y análisis de una actividad artística / educativa desarrollada en la actualidad, se observó que Escolinha fue y es un espacio donde se trabajan experiencias estéticas sensoriales desde la perspectiva de la inclusión.

Palabras-clave: Arte; Educación; Inclusión.

\section{INTRODUÇÃO}

A educação, conforme a Carta de Direitos Humanos (1948) é um direito universal que deve ser garantido a todas as pessoas, independente de etnia, condição social, cultural e condição de saúde. Por muito tempo, as pessoas com deficiência foram afastadas do acesso a esse direito. Em consequência foram sendo colocadas às margens da sociedade e foram privadas de serem acompanhadas em seu processo de desenvolvimento humano. Essa realidade, para a felicidade, vem mudando consideravelmente desde o final do século XX, em que se tem registro de mobilizações sociais em prol de reverter a situação do não acesso à educação por parte das pessoas com algum tipo de deficiência.

No Brasil, graças às mobilizações sociais e apoio de alguns políticos, são fomentadas leis que possibilitaram aberturas para a modificação da realidade descrita anteriormente. Com o maior envolvimento dos setores: civil, acadêmico e econômico, o acesso de pessoas com deficiência à educação toma impulso e passa a ser viabilizada, em específico, na década de 1990. Para pensar a inclusão social, no âmbito das deficiências, primeiro foi preciso pensar o acesso à educação, dessa maneira foram determinadas leis que garantem acessibilidade em espaços educativos, como a Lei Federal № 7.853 (1989), que dispõe sobre o apoio às pessoas portadoras de deficiência, sua integração social; a Lei № 8.213 (1991) - que garantiu o acesso da pessoa com deficiência ao mercado de trabalho; a Lei de Diretrizes e Bases № 9.394 (1996) - que apresenta, em seu bojo, questões referentes ao ensino de pessoas com deficiência.

Para que essas leis vigorassem efetivamente, foi preciso pensar na formação de profissionais que lidariam com esse público específico. Desta forma surgiram em todo país cursos regulares de Linguagem Brasileira de Sinais (LIBRAS), Linguagem Braile e, na academia, cursos de Licenciatura em LIBRAS e especializações voltadas à Educação inclusiva, dentre outros.

Pensando nessa perspectiva de formação profissional, busquei participar do curso de "Especialização em Educação Especial na Perspectiva Inclusiva", da Universidade de Pernambuco (UPE), a fim de compreender melhor como poderia desenvolver projetos educativos no âmbito da educação inclusiva na Escolinha de Arte do Recife (EAR ), instituição que passei a atuar como voluntário. Por meio de leituras, vivências docentes e participando de rodas de conversas, entrei em contato com questões pertinentes à didática do ensino da arte para pessoas com deficiência.

Tomando por referência as experiências arte/educativas desenvolvidas na Escolinha de Arte do Recife (EAR ${ }^{1}$ ), espaço que desde sua fundação tem como missão aco-

${ }^{1}$ Doravante utilizarei essa sigla para me referir à Escolinha de Arte do Recife. 
Iher toda diversidade de público, por isso, eu considero importante fazer um registro de uma das práticas pedagógicas adotadas pela instituição, na contemporaneidade, que foi considerado o caráter inclusivo.

Sabendo que a EAR foi pioneira a adotar ações arte/educativas na perspectiva inclusiva conforme registra Fernando Antônio Azevedo (2000), acreditamos ser importante para o campo da educação, dialogar alguns autores que versam sobre a história da Educação inclusiva para compreender a trajetória da EAR e as contribuições dela para o avanço do pensar práticas arte/educativas na perspectiva inclusiva na contemporaneidade, ajudando a fortalecer as recentes mobilizações de políticos, da sociedade civil e Academia por garantias de direitos básicos, em específico direito à educação, para as pessoas com deficiência.

\section{FUNDAMENTAÇÃO TEÓRICA}

\subsection{A TRAJETÓRIA DA EDUCAÇÃO ESPECIAL INCLUSIVA NO BRASIL}

No Brasil, conforme registros históricos até o século XVIII, a ideia de deficiência física ou psicológica era estritamente justificada pelo misticismo e ocultismo (religião). As diferenças não eram compreendidas por base científica, que promovesse o reconhecimento da diversidade de condições das pessoas como sendo condições biológicas. Conforme comenta Marcos José Silveira Mazzotta (1996), no passado, a religião possuía uma grande força cultural, ela definia perspectivas cristãs considerando-as universais, para justificar tudo que existia no mundo. As Sociedades ocidentais foram sendo desenvolvidas na área arquitetônica, cultural e política de acordo com as perspectivas discriminatórias e excludentes.

No Brasil tal perspectiva sobre as pessoas com deficiência também foi adotada no processo de construção da colônia e só se transformou, segundo Mazzotta (1996) a partir do contato com os pensamentos europeus desenvolvidos no século XIX, trazidos pelo representante da coroa portuguesa. Essa nova perspectiva, como observado o autor, ficou mais evidente no campo da educação, quando em 1854 foi instituído o atendimento escolar especial aos portadores de deficiência teve seu início no Brasil: “(...) em 12 de setembro de 1854 decreto imperial nำ1428, D. Pedro II fundou, na cidade do Rio de Janeiro, o Imperial instituto dos meninos cegos" (SILVEIRA, 1996, p. 28). D. Pedro II ainda criou através da lei n-839 de 26 de setembro de 1857, também no Rio de Janeiro, o Imperial Instituto dos Surdos-Mudos. Em ambos, segundo Silveira (1996) foram promovidas oficinas para a aprendizagem de ofícios e isso pode sinalizar uma preocupação do império em formar trabalhares, pessoas produtivas para a sociedade.

A iniciativa do imperador brasileiro estimulou posteriormente, na primeira metade do século XX, até 1950, a criação de quarenta estabelecimentos de ensino regular mantidos pelo poder público, um federal e os demais estaduais. Essas escolas segundo Silveira (1996) prestavam atendimento escolar especial a "deficientes" mentais ou físicos. Após esse período inicial, o autor relata que surgiram mais catorze estabelecimentos de ensino regular. Dentre o total de cinquenta e quatro estabelecimentos 
de ensino regular, podemos destacar duas instituições sediadas em Pernambuco, o Instituto de Cegos, criado em 1935, e a Escola Especial Ulysses Pernambucano, especializada em "deficientes mentais", instalada em 1941. Tais instituições, segundo Silveira (1996), foram importantes para a construção do pensamento de uma educação inclusiva no Estado de Pernambuco.

No campo da arte/educação novas experimentações foram surgindo pautadas pela interação entre as áreas de conhecimento: arte, pedagogia e medicina. Essas experimentações resultaram, como vamos observar a seguir, origem a novos processos terapêuticos e de ensino e aprendizagem voltados para pessoas com deficiência. Sobre esse período vale ressaltar a importância da arte, apreciação e prática artística, para o desenvolvimento de métodos educativos que buscaram humanizar os processos educativos.

\subsection{MOVIMENTO ESCOLINHA DE ARTE (MEA) E A EDUCAÇÃO ARTÍSTICA NO BRA- SIL}

Para compreendermos a atuação da EAR no campo da Educação inclusiva, é preciso conhecer a origem de seu pensamento e formato pedagógico. Destarte, iremos apresentar registros sobre o Movimento Escolinha de Arte surgida em 1948. Procurando instituir um modelo de escola de ensino da arte diferente, conforme relata Maria Betânia e Silva (2013); surge a Escolinha de Arte do Brasil (EAB), uma instituição voltada especificamente para o ensino da arte. Fundada por Augusto Rodrigues (pernambucano); Lúcia Alencastro Valentim (gaúcha) e Margareth Spencer (norte-americana), o MEA se preocupou com o ensino da arte para crianças, jovens, adultos e pessoas com deficiência. A EAB prestou também a função de instituição formadora de arte-educadores.

Antes do advento do surgimento do MEA, em 1930, a educação artística especializada para crianças e adolescentes era oferecida por artistas, em seus ateliês. Ana Mae Barbosa (2011) registra que o ensino não formal da arte nesse período era baseada na perspectiva da "livre expressão" e espontaneidade. Então, meio a essa realidade a nova perspectiva o MEA eclode partir de 1947, com a missão de introduzir um novo formato de ensino da arte no sistema educacional brasileiro. Tal movimento impulsionou mais ainda o surgimento de espaços educativos voltados para crianças, isso em várias cidades do Brasil. Esses espaços, geralmente comandados por artistas, focavam-se na percepção e aprendizagem da arte como ferramenta para expressar emoções, servindo por vezes como atividade terapêutica para crianças e adultos com ou sem deficiência. 
Figura 1 - Roberto Almeida, Augusto Rodrigues, Anísio Teixeira e Heitor dos Prazeres discutindo Arte Popular

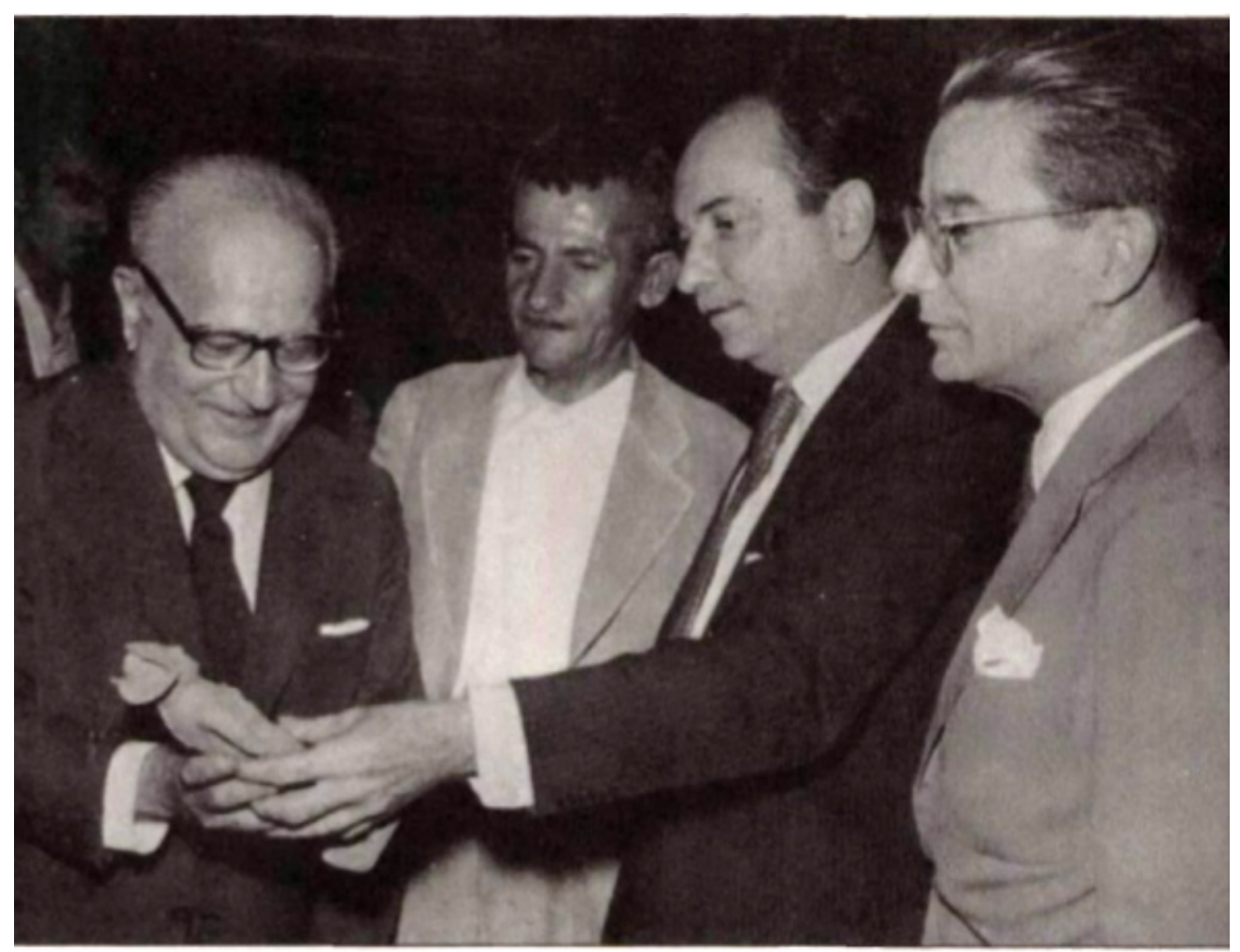

Renato Aumeide. Vitalino. Augusto Aodrigues. Anivio Teixeira e Meitor dos Prazeres - arte popular e educaçlo.

Fonte: http://www.dominiopublico.gov.br/download/texto/meo02413.pdf (2018)

Ainda sobre o MEA, Silva (2013) afirma que fundado no pensamento modernista, o movimento desenvolvia estudos correlacionando a arte com a filosofia, a psicologia, a antropologia, a história da arte e a mitologia, no o intuito de aprofundar a compreensão sobre o artista, sua obra, sua época e uma compreensão da arte em sua dimensão. Assim, as atividades educativas desenvolvidas nas Escolinhas de Arte buscavam ir além da simples prática artista, elas buscavam formular e aplicavam outras atividades lúdicas como jogos, brincadeiras, encenações teatrais, etc. a fim de complementar o processo de desenvolvimento do indivíduo humano.

Sobre as atividades lúdicas desenvolvidas nas Escolinhas destacamos a contribuição pedagógica destas no sentido de que elas valorizavam as emoções do indivíduo, conforme Silva (2013) comenta a sistematização do jogo livre e espontâneo, com materiais e elementos da linguagem gráfica e plástica, contribuíram para o desenvolvimento emocional e intelectual da criança, e gerou experiências educativas relevantes para o pensamento sobre a educação artística na Inglaterra, na França e América Latina.

\subsection{A ESCOLINHA DE ARTES DO RECIFE E A PERSPECTIVA INCLUSIVA DA PESSOAS COM DEFICIÊNCIA}

Em Recife, seguindo a tendência do MEA, surgiu em 6 de março de 1953 a EAR. A fundação da instituição se deu sob a iniciativa de Augusto Rodrigues e Aloísio Ma- 
galhães. A história da EAR começa, conforme relata Silva (2013), nas dependências da Escola Especial Ulysses Pernambucano, a única instituição oficial voltada para pessoas com deficiência (educação com viés terapêutico) no Nordeste. Sob a direção de Noemia de Araújo Varela, a Escola Ulysses Pernambucano, até 1949, foi um espaço onde foram organizadas e orientadas a criação e execução de experiências pedagógicas inovadoras que tiveram como objetivo integrar a arte ao processo educativo de pessoas com deficiência mental. Utilizando o espaço para a prática de atividades artísticas como: desenho e pintura. Reconhecendo os resultados positivos das experiências de Varela na Ulysses, as experiências de artistas e outros profissionais das áreas de Educação, logo foi fomentada a ideia de fundar no Recife uma instituição educativa colaborativa, sem fins lucrativos e que tivesse autonomia, aos moldes da Escolinha de Arte carioca.

Figura 2 - Escolinha de Artes do Recife.

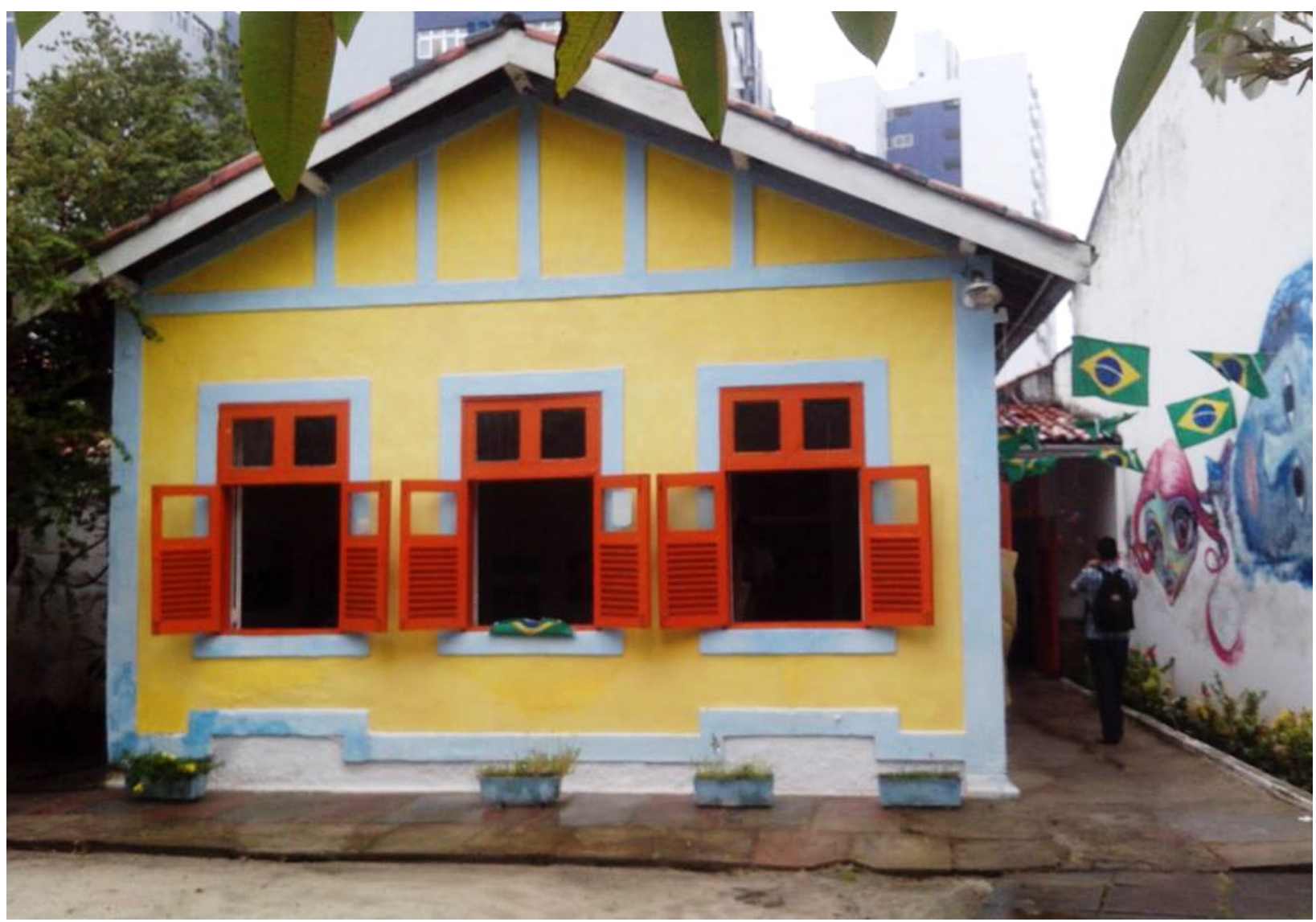

Fonte: Acervo particular do autor (2014)

Como as outras Escolinhas do MEA, o objetivo principal da instituição recifense foi formar as crianças e educadores em arte. Visou educar e motivar a criança, ajudando-a a desenvolver as habilidades, a flexibilidade, a intuição; em quanto que buscou formar o educador através da ação de incluí-lo no processo criativo da prática pedagógica com vista na construção da totalidade e unicidade da criança. As intenções da Escolinha eram - e continuam sendo - fundamentalmente voltadas para o desenvolvimento artístico, cultual, estético, social, cognitivo, etc., do indivíduo.

A estruturação pedagógica e administrativa da escolinha, segundo afirma Silva (2013) foi respaldada nas experiências de Noemia Varela obtidas a partir do contato 
dela com a EAB e a Escola Ulysses Pernambucano. As práticas que foram implementadas por ela, enfatizam a política de inclusão da instituição e ampliaram a visão sobre os métodos educativas, concretizando, segundo Azevedo (2000), o desejo particular dela de possibilitar o acesso à experiência artística de diferentes sujeitos, independentemente de suas particularidades.

Assim, conhecendo as intenções da instituição, podemos dizer que as ações arte/educativas desenvolvidas na EAR podem ser consideradas como ações inclusivas que visaram, por meio da arte, viabilizar a expressão e comunicação de alunos com particularidades motoras, visuais, auditivas. Como observado pelos autores, desde o início de sua formação, a Escolinha teve como diretriz a inclusão, ela se configurou como um espaço aglutinador das diversidades, crianças, adultos e idosos, com ou sem deficiências. Com essa filosofia inclusiva de Noêmia Varela à EAR, segundo Silva (2013), promovia ações qualitativas para todo tipo de pessoa visando o desenvolvimento estético e artístico dos frequentadores, respeitando as particularidades de cada um. A autora frisa ainda que elas incentivavam o ajustamento emocional e social de seus alunos e visava promover ações de mobilizações e integração de processos psíquicos à arte na educação.

Nesse sentido a Escolinha de Arte do Recife, assim como outros espaços educativos não formais, como ONG's, Galerias de Arte, Museus, Cursos livres, é um espaço que ganha relevância dentro do sistema educacional, pois, na contemporaneidade, o que se percebe é um movimento por transpassar os processos educativos desenvolvidos no âmbito formal, ou seja, há uma busca por uma formação que vá além do currículo formal, conteudista. Segundo Maria da Glória Gohn (2010), a educação não formal vem se consolidando desde o final do século XX e a justificativa para essa realidade advém das mudanças e transformações ocorridas na sociedade, especialmente após o surgimento da ideia de globalização, disseminada no período.

As responsabilidades da educação formal (assim definida por possuir um modelo educativo que obrigatoriamente deve cumprir com as diretrizes institucionais do Estado e da Direção escolar) são sistematizadas e, na maioria das vezes, acaba não sendo eficientes, ao não atingirem os objetivos educacionais. Essa ineficiência se deve à adoção de abordagens engessadas de ensino, pelas experiências educativas que acabam por não se relacionarem com o ambiente (realidade) na qual o indivíduo está inserido.

Diante disso, os espaços não formais, como a EAR, se colocam como suporte para a educação formal, atendendo demandas educativas ignoradas pelas escolas. Nesse sentido, a autora vai dizer que ela deve acontecer em paralelo com a educação formal, para que o indivíduo desenvolva diferentes dimensões da existência. Reforça ainda esta ideia ao afirmar que "o ideal é que a educação não formal seja complementar (...). Complementar no sentido de desenvolver os campos de aprendizagens e saberes que lhes são específicos. Pode e deveria atuar em conjunto com a escola". (GOHN, 2010, p.40). 


\section{DESENVOLVIMENTO}

O processo de elaboração da pesquisa ocorreu por meio de três metodologias que nortearam as ações investigativas: Pesquisa Bibliográfica, Documental e a A/R/ tográfica. Por meio delas obtemos informações sobre a configuração das atividades inclusivas da EAR e suas contribuições. Seguindo a ideia sobre pesquisa histórica e documental de Jorge Duarte (2006), investiguei registros bibliográficos e arquivo documental da escolinha para levantar informações sobre a fundação da instituição, do tempo de atuação e principalmente identificar a relação dela com o pensamento da educação na perspectiva inclusiva. Após o levantamento dessas informações, a fim de validá-las procurei observar as práticas arte/educativas desenvolvidas por ela.

Então, ao observar práticas arte/educativas desenvolvida na EAR pelas arte/educadoras Auvaneide Carvalho e Zanaide Ramos, pude compreender a visão pedagógica de Noêmia Varela registrada em literaturas, constatei a relevância da abordagem do ensino da arte como experiência para o atendimento formativo de algumas pessoas com deficiência. Para observar a relação da instituição com o ensino de pessoas com deficiência precisei passar um período de três meses de convivência no local, atuando como arte-educador e pesquisador. A partir das observações das práticas, busquei referências teóricas para desenvolver uma atividade arte/educativa na perspectiva inclusiva com um grupo de crianças.

\subsection{EDUCAÇÃo NA PERSPECTIVA INCLUSIVA: PRÁTICA ARTE/EDUCATIVA DA EAR}

Em alguns espaços como a EAR, a prática de ações arte/educativas (oficinas e cursos regulares) desenvolvidas, contribui para o desenvolvimento estético, cultural e social do indivíduo, podemos identificar a contribuição da arte para o processo de desenvolvimento da pessoa, a partir do momento que a educação artística cumpre, junto a outras disciplinas abordadas na escola, a missão de questionar pensamentos estabelecidos e propagados de forma acrítica.

Partindo do contexto apresentado sobre a escolinha podemos descrever agora uma atividade arte/educativa desenvolvida nela, realizada em maio de 2018, com turma de crianças com idades entre 6 a 9 anos. Para a turma especificada foi realizada uma atividade de construção coletiva de visualidades de uma paisagem sonora utilizando-se da técnica artística de colagem. Sabendo que a instituição não faz distinção entre as crianças (seja por condição social, étnica, gênero ou condição biológica), dada a temática de Paisagem sonora, abordada pela atividade, vale salientar que na turma observada havia a presença de duas crianças com deficiência, e por causa disso a proposta pedagógica foi elaborada levando-se em consideração as potencialidades das mesmas.

Essa maneira de pensar as propostas pedagógicas, segundo Azevedo (2019), parte de uma visão da Noemia Varela, que orientava os arte-educadores a tratar todas as crianças por igual, sempre com amor e carinho, no âmbito social e no pedagógico. No campo pedagógico Varela partia do interesse da criança e buscava ajudá-la a desenvolver suas habilidades, acolhendo a todos, como registra Azevedo (2019) "em 
seu coração de arte/educadora cabiam todos os deserdados da escola, dessa escola que mata as singularidades" (AZEVEDO, 2019, p.107), Varela tinha como diretriz pedagógica "olhar para o outro, pelo ângulo de suas potencialidades e nunca pelo de suas deficiências" (AZEVEDO, 2019, p.107). Assim, precisamos registar que a perspectiva de Varela foi e ainda é adotada pelos arte-educadores da EAR que buscam, em parceria com as famílias das crianças, estabelecer uma formação inclusiva propício ao desenvolvimento de habilidades artísticas.

A proposta observada neste artigo foi desenvolvida a partir do planejamento da arte-educadora Auvaneide Carvalho, que no período do curso regular de 2018, estava trabalhando os sentidos do corpo humano nas percepções de produções artísticas. As ações educativas desenvolvidas, portanto, vislumbraram desenvolver a percepção dos sentidos sensoriais nas e pelas produções artísticas.

Durante os encontros a participação de crianças com deficiência nas atividades arte/educativas desenvolvidas na EAR, visou colocar o/a participante em contato com o mundo concreto, com outros indivíduos, de forma que elas se sentissem acoIhidas. Acreditamos que por este contato com outras realidades foram estabelecidas praticas dialógicas que estimulem o compartilhamento de experiências, pensamentos e gostos estéticos. Então, com os momentos de diálogo promovidos durante o curso, os participantes encontravam semelhanças, um denominador comum, que parte do gosto pela arte.

Para o desenvolvimento da proposta o intuito foi primeiramente conversar com as crianças sobre: o som, sonoridade, a partir da perspectiva artística e poética, destacando a relação das cores e formas com a vibração, timbre e modulação do som. Por se tratar de uma turma composta por cinco crianças, entre 6 e 9 anos, os conceitos foram abordados de forma lúdica, com brincadeiras e jogos, pois acreditamos que desta maneira o aprendizado acontece de forma espontânea, pratica e direta. Ratificamos nossa crença na fala de Juan Antônio Moreno Murcia na qual diz que "o valor de aprendizagem espontânea que tem a brincadeira, ou seja, [podemos] considerá-la como instrumento com poder suficiente para provocar a aquisição espontânea de novas habilidades e conhecimentos" (MURCIA, 2005, p.43)

Dentre os conceitos apresentados trabalhei os conceitos de paisagem sonora e ambiente sonoro. Busquei referência sobre ambientes sonoros, no livro The soundscape de Raymond Murray Schafer (1994). Em seu livro, Schafer (1994) comenta que a criação desses espaços é dinâmica, pois se dá pela relação do homem com o som ambiental (natural), ou seja, a paisagem sonora está em constante transformação devido às interferências do homem. Para pensar a construção de uma paisagem sonora, conforme relaciona o autor, faz-se necessário considerar as possíveis interferências sonoras que compõe uma paisagem.

Visando estimular a percepção das crianças, busquei promover uma atividade de assimilação da ideia de paisagem sonora, através de uma dinâmica onde os participantes teriam que identificar um ambiente da Escolinha, a partir do ouvir de uma narração/emissão de sons presentes nesse ambiente. Essa atividade desenvolveu a percepção das crianças para com as formas, cores, objetos e sons (humanos, de instrumentos, etc.) presentes ao redor delas, passando assim a perceber como o estímulo sonoro interfere na produção de uma imagem mental. 
Dando continuidade a proposta pedagógica, num segundo momento foi colocado um áudio de uma área urbana, com vários sons vibrantes como o som de veículos, buzinas, passos e vozes humanos, explosões etc. Com esse áudio pretendeu-se que as crianças estabelecessem auditivamente as diferenças entre ambientes urbanos e não urbanos, entre ambientes que elas tinham frequentado e outras situações vivenciadas. Essa atividade serviu de suporte, como será visto, para o debate sobre as interferências do homem no ambiente, na construção desse ambiente.

Sabendo que a EAR ainda mantém como objetivo principal trabalhar a criança, desenvolvendo nela a fluência, a flexibilidade, a intuição, "construção da totalidade e unicidade harmônica que contribuem para o desenvolvimento individual e coletivo" (SILVA, 2013, p.42). Estabeleci uma atividade coletiva, a saber: de elaboração de um painel da paisagem sonora urbana que promovesse a reflexão sobre a interferência do homem no ambiente que habita. Então, a partir da percepção do som frenético de veículos e dos ruídos das vozes humanas (vendedores de pipocas e demais comerciantes), as crianças elaboraram mentalmente paisagens sonoras associando os sons às imagens do próprio imaginário. As crianças associaram os ruídos aos torcedores murmurando num estádio de futebol, a um trovão, a uma explosão, etc. E buscaram retratar essas associações através de recortes de imagens de jornais e revistas, que compuseram um painel, materializando uma paisagem sonora.

Dentre os sons percebidos uma das crianças identificou o frágil canto de um pássaro, conforme podemos ver na figura 03, a seguir. Foi a partir da imagem de um pássaro recortado por esta criança que iniciamos o processo de leitura e contextualização do trabalho que estava sendo desenvolvido por elas. A produção do painel, por meio de colagem, foi norteada pela discussão de como o homem interfere na natureza (ambiente) ao ponto de não conseguirmos ouvir os pássaros, ou ver o brilho das estrelas. Gerou-se a partir do trabalho a reflexão sobre as relações éticas do homem com a natureza, noções de respeito e preservação do meio ambiente, poluição sonora, e residual. Também foi comentado sobre a capacidade do ser humano de transformar realidades coletivas.

Figura 3 - Produção de painel de paisagem sonora urbana.

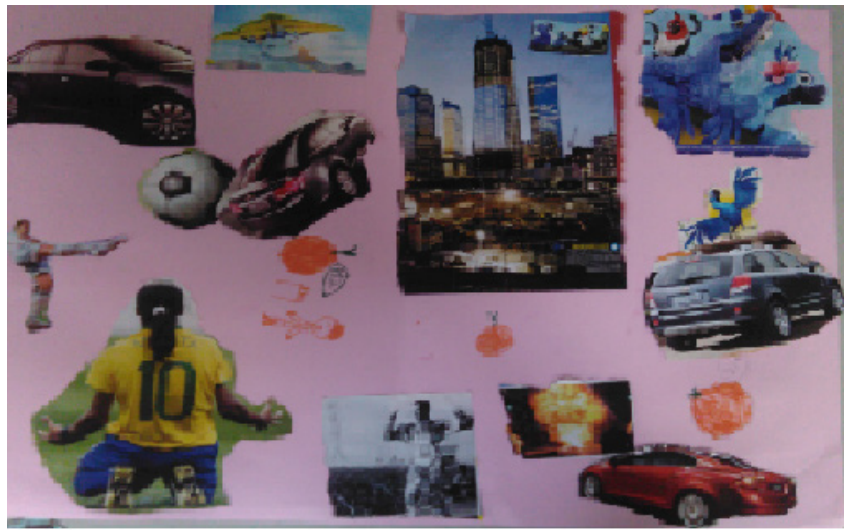

Fonte: Acervo do autor. (2018). 
Figura 4 - Prática arte/educativa na EAR

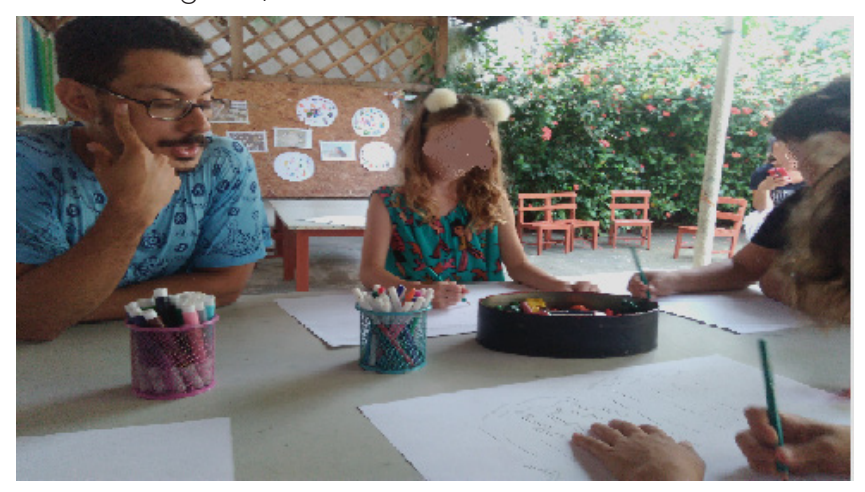

Fonte: Acervo particular do autor (2018)

Visto que o ensino da Arte na EAR preza pela interpretação, problematização e compreensão das imagens (físicas, virtuais, sonoras, corporais) fizemos uso da Abordagem Triangular em suas ações, pois esta abordagem, conforme afirma Fernando Antônio Azevedo (2016), se "propões a leitura do discurso tanto da imagem produzida como obra de arte quanto da imagem produzida como cultura visual" (AZEVEDO, 2016, p.95). Nesse sentido, fica justificado a abordagem didática e pedagógica aplicada pelas etapas de ensino das Artes da Abordagem Triangular, de Ana Mae Barbosa (2014): Leitura, Contextualização e Fazer artístico, a partir da cultura visual dos participantes.

Acreditamos que seja qual for o espaço educativo, as ações artísticas devem estabelecer vínculos com os aprendizes e suas culturas visuais, conforme salienta Fernando Hernandez (2000), nesse sentido é essencial que educação do olhar crítico e humanizado, nas artes, parta das percepções próprias, das próprias possibilidades, pois cada ser reproduz e interpreta imagens a partir de seu acervo visual, da própria cultura visual e experiências. O acervo da cultura visual do participante tornou-se algo imprescindível no processo de construção de conhecimento apresentado, pois visou-se promover "uma interpretação não é só verbal ou visual (...). Interpretar implica relacionar biografia de cada um com artefatos visuais, com os objetos artísticos ou produtos culturais com os quais se relaciona" (HERNANDEZ, 2000, p. 49).

O processo de construção do conhecimento do conhecimento, dado pela Abordagem Triangular, ocorreu, como visto, levando-se em consideração as habilidades já possuídas pelas crianças. Registramos que ao se ajudarem as crianças com ou sem deficiência interagiram entre si no momento de identificação dos sons e de assimilação com as imagens, também interagiram no processo imaginativo de construção da paisagem visual por recortes. Desta maneira ao ter sido desenvolvida coletivamente, onde todas as representações foram se encaixando por meio de um consenso conversado entre elas também foram desenvolvidas as relações entre personalidades, a autoestima, as relações interpessoais, a tolerância e o respeito. 


\section{CONCLUSÃO}

A EAR foi fundada em 1953, por um grupo de educadores que desde fundação se empenharam no processo de educação artística para pessoas com ou sem deficiência. Atualmente, a instituição mantém alguns valores e abordagens pedagógicas pensadas pela Noemia Varela, principal representante da arte/educação. Tendo em vista a presença da perspectiva inclusiva desta arte-educadora, as práticas de ensino desenvolvidas no âmbito não formal tiveram e têm na contemporaneidade, como apresentado, o objetivo de construir uma sociedade mais justa, inclusiva e tolerante através da arte. Como fica claro na missão da instituição ao atender, sem fins lucrativos, o público em geral, crianças, adultos, pessoas com deficiência, estudantes e educadores. A EAR é um espaço que permite as experiências concretas de interação entre academia e sociedade, possibilitando novas visões sobre formas de fazer Arte/ educação.

A atividade arte-educativa apresentada, partiu desse caráter da Escolinha, respeitando as diretrizes metodológicas e pedagógicas da instituição para promover experiências estéticas sensoriais. Trabalhando a percepção auditiva e a relação som imagem, pela via do lúdico e da convivência em grupo, como apresentado, a abordagem adotada proporcionou a inclusão de pessoas com deficiência, contribuindo para formação estética e social ao proporcionar o contato com técnicas artísticas a fim de desenvolver habilidades coletivamente.

Desta maneira podemos concluir que como instituição atuante no campo da Arte/educação, o trabalho que a EAR, desde sua fundação, vem desenvolvendo faz uso da arte como ferramenta de desenvolvimento humano, estético, ético. Respeitando a pluralidade de existências. Através dos registros apresentados fica evidenciado que a instituição pesquisada além de atuar como espaço formativo de pessoas interessadas em aprender arte, atua também como um tipo de laboratório para acadêmicos que investigam o Ensino da Arte e Educação na perspectiva inclusiva. ${ }^{2}$

\section{REFERÊNCIAS}

AZEVEDO, Fernando A. Gonçalves de. Noemia Varela, um réquiem para (não) dizer (a)deus. Em: Mulheres não devem ficar em silêncio. Ana Mae Barbosa e Vitória Amaral (Orgs.). São Paulo: Editora Cortez, 2019. pág. 97.

Fernando A. Gonçalves de. A Abordagem Triangular no ensino das artes como teoria e a pesquisa como experiência criadora. Recife: Editora SESC, 2016.

\section{BARBOSA, Ana Mae. A imagem no ensino da Arte. São Paulo: Perspectiva. 2014. Ana Mae. O ensino da arte no Brasil: aspectos históricos e metodoló- gicos. Material didático da rede de ensino estadual de São Paulo. Módulo 1. Proje-}

\footnotetext{
2 Revisão gramatical realizada por Adriana Janaina da Silva Baé. Licenciatura em Letras, pela Universidade Federal de Pernambuco (2016), e-mail: adrianajanaina89@gmail.com. Curriculo Lattes: http://lattes.cnpq.br/2412823826132930
} 
to de formação de professores da UNESP. 2011. Disponível em https://acervodigital. unesp.br/bitstream/123456789/40427/3/2ed_art_m1d2.pdf Acessado no dia 20 de julho de 2019. 19horas.

DUARTE, Jorge. Barros, A. (Orgs.). Métodos e técnicas de pesquisa em ComunicaÇão. São Paulo: Atlas. 2006.

GOHN, Maria da Glória. Educação não formal e o educador social. São Paulo: Cortez Editora. 2010

HERNANDES, Fernando. Cultura visual, mudança educativa e projeto de trabalho. Porto Alegre: Editora Artmed. 2000.

MAZZOTTA, Marcos José Silveira. Educação especial no Brasil. História e politicas públicas.. São Paulo: Cortez Editora. 1996.

MURCIA, Juan A. Moreno. Aprendizagem através dos jogos. Porto Alegre: Artmed. 2005

SILVA, Maria Betania e. Memórias não são só memórias: a escolinha de arte do Recife (1953-2013). Recife: Editora Universitária (UFPE). 2013.

SCHAFER, Raymond Murray. The soundscape - our sonic environmental and tuning of the world. 2.ed. Rochester (EUA): Destiny Books - Edição Kindle, 1994.

Recebido em: 20/01/2020

Aceito em: 08/05/2020 